\title{
Optimizing post-acute care in breast cancer survivors: a rehabilitation perspective
}

This article was published in the following Dove Press journal: Journal of Multidisciplinary Healthcare 30 August 2017

Number of times this article has been viewed

\author{
Bhasker Amatya ${ }^{1-3}$ \\ Fary Khan ${ }^{1-3}$ \\ Mary P Galea ${ }^{1-3}$ \\ 'Department of Rehabilitation \\ Medicine, Royal Melbourne Hospital, \\ ${ }^{2}$ Australian Rehabilitation Research \\ Centre, Royal Melbourne Hospital, \\ ${ }^{3}$ Department of Medicine, The \\ University of Melbourne, Parkville, \\ VIC, Australia
}

\begin{abstract}
Breast cancer (BC) is the most common malignancy and a leading cause of morbidity and mortality in women worldwide. Therapeutic advances and improved survival rates of women with $\mathrm{BC}$ have implications for long-term impact on disability, psychological function and quality of life (QoL), which may be amenable to rehabilitation. The focus of rehabilitation is on managing disability, reducing sequelae and symptoms, and enhancing participation and societal reintegration, to achieve the highest possible independence and the best QoL. Rehabilitation interventions should be considered early for maintaining functional capacity and reducing the risk of losing important abilities or independence and should be individualized depending on disease phase, functional deficits, personal requirements and specific goals. A number of interventions have been trialled to support rehabilitation input for women with $\mathrm{BC}$, which include physical therapy, psychological interventions (psychotherapy, cognitive behavioral training) and others. Multidisciplinary rehabilitation and uni-disciplinary interventions such as physical therapy have been shown to be beneficial in reducing disability, and improving participation and QoL. There is a need for comprehensive assessment of health domains in BC patients using a standardized framework and a common language for describing the impact of disease at different levels, using the International Classification of Functioning, Disability and Health core sets. This will provide more detailed information on the needs of these patients, so more efficient and targeted rehabilitation interventions can be provided.
\end{abstract}

Keywords: breast cancer, rehabilitation, disability, participation

\section{Introduction}

Breast cancer (BC) is the most common malignancy in women and a leading cause of morbidity and mortality. ${ }^{1}$ There are $\sim 1.38$ million new cases of $\mathrm{BC}$ ( $23 \%$ of all cancers) and 458,000 BC-related deaths per year worldwide. ${ }^{1} \mathrm{BC}$ is the most diagnosed cancer and cause of cancer-related death among women in Australia, with almost 11,000 new cases and over 2,500 deaths annually. ${ }^{2}$ The incidence of $\mathrm{BC}$ is on the rise, ${ }^{3}$ with an estimated 1 in 8 Australian women will be diagnosed with $\mathrm{BC}$ by the time they turn 85 years. $^{2}$ Due to early detection and therapeutic advances in management, BCrelated mortality rates have declined significantly and the majority of women make a good functional recovery after treatment. ${ }^{4}$ Surgery, radiotherapy, chemotherapy and/ or hormonal therapy are main treatment options. ${ }^{5} \mathrm{BC}$ survival rates vary between $40 \%$ and $80 \%$ in low and high income countries, respectively. ${ }^{1}$

The World Health Organisation (WHO) endorses a BC control program integrating prevention, early detection, diagnosis, treatment, rehabilitation and palliative care..$^{3,6}$ Rehabilitation is a "problem-solving educational process aimed at restoration of skills
Correspondence: Bhasker Amatya Department of Rehabilitation Medicine, Royal Melbourne Hospital, 34-54 Poplar Road, Parkville, VIC 3052, Australia

$\mathrm{Tel}+61383872037$

Fax +6I 383872222

Email bhasker.amatya@mh.org.au 
to regain maximum self-sufficiency and function, reducing disability and limitation in participation". ${ }^{7}$ It aims to improve patients' function, participation and quality of life (QoL). ${ }^{8}$ Rehabilitation is an integral part at all stages of BC management: the early post-operative period, while undergoing all adjuvant therapies; the late phases of care and long-term care continuum in the community. Rehabilitation interventions comprise expert multidisciplinary (MD) assessments evaluated through appropriate outcome measures using functional goal-oriented approaches (such as clinical pathways) to target patient priorities. Goal setting is an integral part of rehabilitation to help the persons achieve the maximum degree of return to their previous level of functioning within limits imposed by their residual physical, functional and cognitive impairments. It encourages participants to set their own goals and priorities, and supports team communication and coordination.

Existing clinical guidelines and frameworks for BC recommend comprehensive, flexible coordinated MD care and appropriate follow-up, education and support for patients and carers. ${ }^{9,10}$ Early referral for rehabilitation enables strategies to ameliorate functional deterioration and enhance participation. ${ }^{10}$ In severely affected individuals, rehabilitation input can provide a modified environment and adaptive equipment to restore some functional independence, along with other key issues such as respite, long-term care and community reintegration. Rehabilitation services should begin early in order to improve the recovery process and reduce disability. ${ }^{3}$

\section{Rehabilitation models}

The main aim of rehabilitation in cancer patients, including individuals with $\mathrm{BC}$, is to restore or maintain optimal physical and psychosocial functions and improve QoL. A number of models for improving the care for people with $\mathrm{BC}$ have emerged worldwide. Some examples of these models are detailed below:

1) The cancer rehabilitation model presents opportunities for intervention throughout the disease continuum phases. ${ }^{11}$ These are:

- Phase I: staging/pre-treatment (patient education, functional preservation of range of movement, mobility aids),

- Phase II: primary treatment (effects of treatment, preserve function, symptom management, e.g., lymphedema, pain),

- Phase III: after treatment-rehabilitation (develop, implement daily routines to restore mobility and self-care, maintenance exercise programs, symptom management),

- Phase IV: recurrence (education, adaptive equipment, exercise, symptom management),
- Phase V: end of life (maintain independence, equipment, education, energy conservation).

2) The International Classification of Functioning, Disability and Health (ICF) defines a common language for describing the impact of disease at different levels. ${ }^{12}$ It describes "functioning" (activity) as the interaction between an individual and their health condition, within the social and personal context in which they reside. It includes the "environmental" factors that interact with all constructs (physical, social and attitudinal environment) in which people live and conduct their lives, and the "personal" factors (e.g., influences or attributes such as self-efficacy) that influence positive adaptation. The ICF model includes the physicians' views of management of complex and interacting symptoms in BC survivors, the therapists' views in terms of managing change in functional status in activities of everyday living, and the perspective of the BC survivors. Within this framework, BC-related impairments (decreased mobility and strength, lymphedema, pain) can limit "activity" or function (decreased ability to carry tasks, inability to self-care), and "participation" (work, family, social reintegration) (Figure 1).

3) Another proposed model for rehabilitation consists of 4 dimensions (concerns and problems, types of rehabilitation, activities and QoL), ${ }^{14}$ with 12 categories and concepts related to rehabilitation. This model was developed following a review of literature and hospital rehabilitation programs (Figure 2).

\section{Issues confronting BC survivors}

Several studies report factors associated with poor level of functioning and participation in women after $\mathrm{BC}$ treatment. These include younger patients, recent diagnosis, aggressive tumor types, chemotherapy, shoulder limitation due to pain and lymphedema. ${ }^{15-18}$ Similarly, participatory limitations (work, social and recreational activity, family life, caregiver stress, activities of daily life) in other BC cohorts have been reported. ${ }^{19,20}$ This information is integral for BC rehabilitation and can be used to aid functional goal-setting and future care planning. However, no single set of proposed indicators accurately predicts long-term outcomes.

With improved survival rates, there are long-term implications of living with residual deficits from $\mathrm{BC}$ treatments that can impact activities of daily living, work, psychological function, social activities and QoL. ${ }^{17}$ Issues related to health, well-being and participation have become increasingly important. In the community, various adjustment issues may surface during transition. ${ }^{21}$ Further, BC survivors have to cope with local symptoms (such as pain, lymphedema, shoulder 


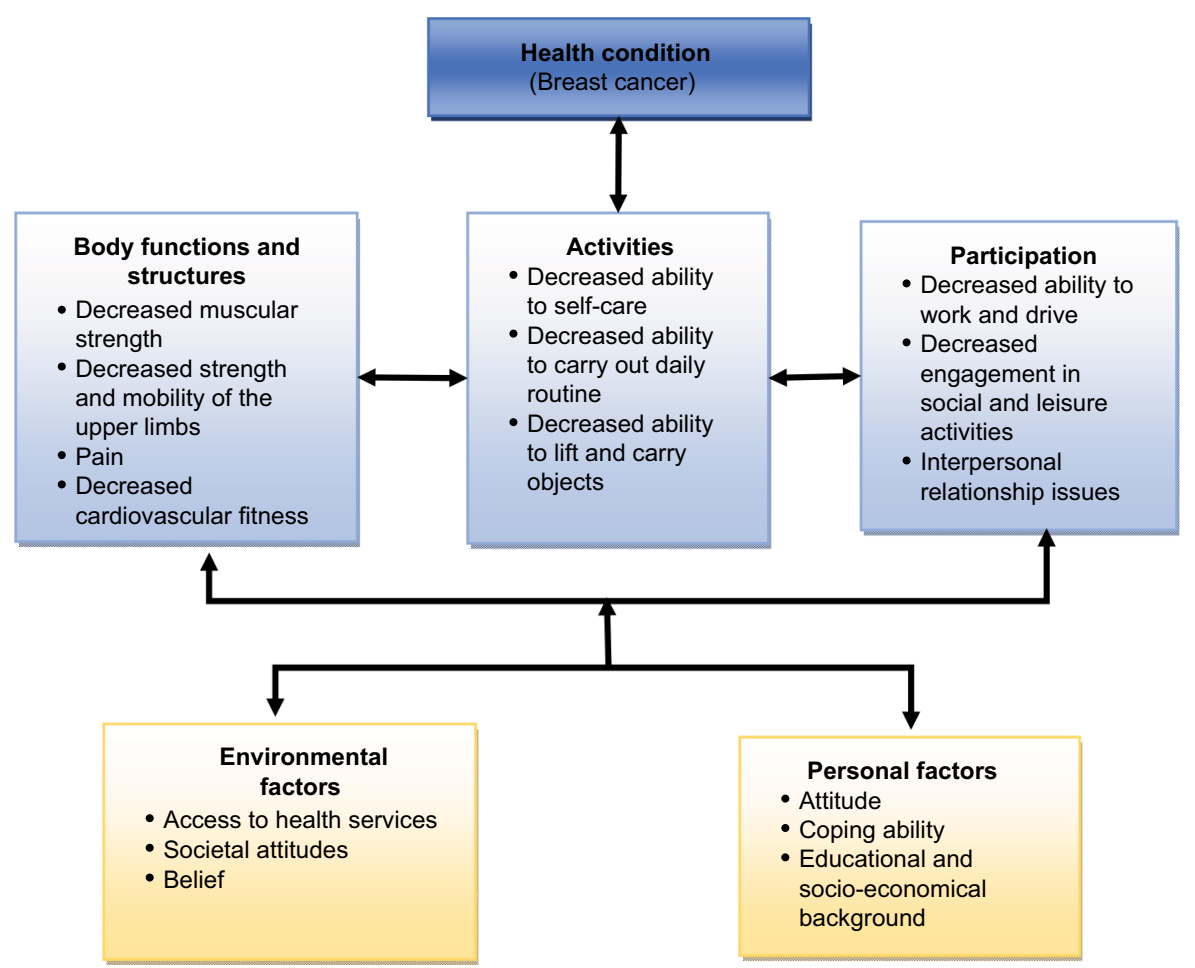

Figure I Interactions between the components of the international classification of functioning, disability and health in breast cancer. ${ }^{13}$

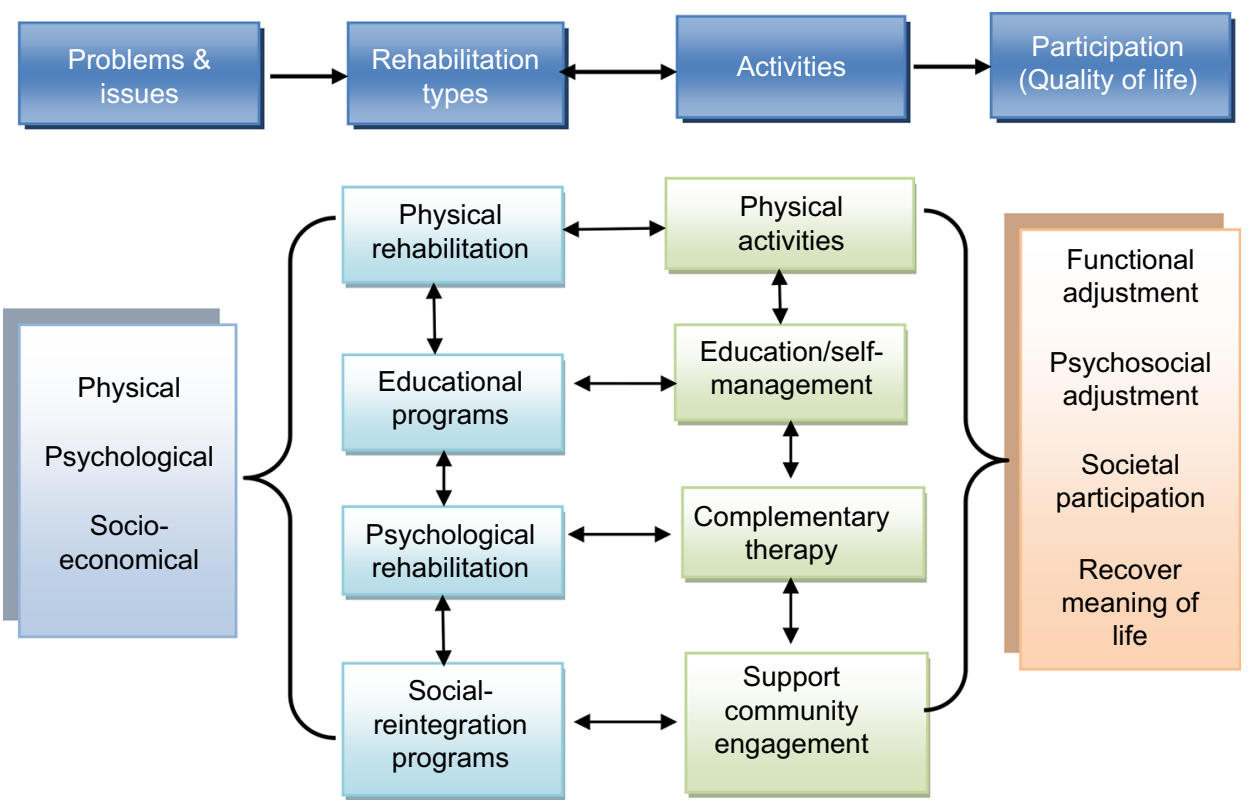

Figure 2 Rehabilitation model for patients with breast cancer.

Note: Data from Chung and Xu. ${ }^{14}$

dysfunction, dizziness, etc.) and various treatment-related consequences and complications, ${ }^{22}$ for example, wound sepsis, seromas and upper limb dysfunction, ${ }^{23}$ cognitive, psychosocial and mood abnormalities, sexual dysfunction and body dysmorphism. ${ }^{24}$ Some of the major issues confronted by the $\mathrm{BC}$ survivors are summarized below:

\section{Pain}

Shoulder and breast-related pain is often a focus of rehabilitation, and may be multifactorial. Shoulder or arm pain can be present in 30\%-40\% of patients at 5-year follow-up, depending on the method of assessment. ${ }^{25-27}$ Contributing causes may include tissue damage, complex regional pain, deep 
vein thrombosis, cellulitis, tendinitis, phantom breast pain, arthritis, etc. ${ }^{14}$ Furthermore, BC treatments (chemotherapy, radiotherapy, medications such as aromatase inhibitors) are potential factors leading to development of neuropathic pain..$^{23,28-30}$ Post-mastectomy pain is not uncommon, and may be unrelated to type of surgery or the usual risk factors. ${ }^{31}$ Pain is dependent on emotional and subjective factors, ${ }^{31,32}$ and prone to psychological and behavioral influences. ${ }^{29} \mathrm{Com}-$ mon upper extremity pain disorders in $\mathrm{BC}$ include cervical radiculopathy, brachial plexopathy, neuropathy, rotator cuff tendinitis, adhesive capsulitis, lateral epicondylitis, postmastectomy pain syndrome, edema and bone metastases. ${ }^{33}$ Caffo et $\mathrm{al}^{34}$ reported post-surgical BC pain in one-third of the patient cohort $(n=529)$, regardless of type of surgery, and demonstrated a negative impact of pain on QoL. Interestingly, a follow-up study (5-6 years) of pain in women who survived $\mathrm{BC}(\mathrm{n}=3088)$ reported an increase in pain symptoms, predicted by psychological factors (depression, adverse life events), while medical factors (type of surgery, stage of BC) played a much smaller role. ${ }^{29}$ Treatment of cancer-related pain should be similar to that for other chronic pain conditions in rehabilitation, addressing physical and emotional factors using a cognitive behavioral approach. ${ }^{35}$

\section{Lymphedema}

Secondary lymphedema is a frequent distressing symptom in women who undergo BC treatment. ${ }^{36}$ It results from excess fluid accumulation in the interstitial space, detrimental tissue changes, upper limb swelling due to physical disruption or compression of the lymphatic channels from surgical resection and/or radiation-induced fibrosis of lymphatic vessels or nodes. ${ }^{37}$ It affects $\sim 6 \%-49 \%$ of women after BC treatment. ${ }^{38-40}$ Lymphedema-associated physical morbidities include: skin changes, pain and loss of sensation and limb function. ${ }^{37,39,41}$ Lymphedema tends to worsen over time and is associated with significant psychosocial morbidity, depression and social inhibition, which compromise daily activities and QoL. ${ }^{36,38}$ A 20-year prospective cohort study $(n=272)$ of women treated with mastectomy and complete axillary dissection, reported that arm infection and injury, and elevated body mass index were significantly associated with development of lymphedema. However, air travel, prolonged carrying of heavy objects and compression did not increase risk in this cohort. Further, occupational and leisure time physical activity (light, moderate and vigorous) are clinically accepted risk factors for the development of lymphedema, but unsupported by longitudinal research. ${ }^{42}$ Rehabilitation strategies for lymphedema include therapeutic exercises, manual lymphatic therapy, compression bandaging, intermittent pneumatic compression, skin care and elevation.

\section{Shoulder range of motion (ROM)}

Upper limb dysfunction is a commonly reported side effect of treatment for $\mathrm{BC} .{ }^{43} \mathrm{~A}$ systematic review examining upper limb dysfunction following BC treatment found a wide variation in the reported prevalence of impaired shoulder ROM (<1\%-67\%), arm weakness (9\%-28\%), shoulder/arm pain $(9 \%-68 \%)$ and lymphedema $(0 \%-34 \%) .{ }^{44}$ Decreased shoulder ROM and strength may persist for many years following treatment, and it is estimated that $15 \%-30 \%$ of survivors have some form of shoulder impairment at 5-year follow-up. ${ }^{25-27}$ The presence of shoulder dysfunction in BC survivors has been found to be associated with lower physical activity, increased body mass index and poorer health-related QoL. ${ }^{13,26}$ Rehabilitation input includes targeted physical and occupational therapy to improve ROM and muscle strength in the shoulder and pectoral girdle.

\section{Fatigue}

Fatigue is a common and distressing symptom reported by cancer patients, including women with BC. ${ }^{45-47}$ Fatigue is experienced by $58 \%-94 \%$ of BC patients during treatment and $56 \%-95 \%$ after they receive adjuvant chemotherapy. ${ }^{46}$ It is frequently persistent, irrespective of tumor control or treatment cessation and correlates with a decline in function. ${ }^{45,46,48}$ Fatigue in BC can be caused by multiple factors, including bio-psychological factors, treatment side effects that are physiologically based, physical de-conditioning, cognitive dysfunction (memory, decreased concentration), distress and depression. ${ }^{45-47}$ Other causes may be treatmentinduced menopause, associated with hot flashes causing sleep disturbances, and other symptoms such as pain and anxiety. ${ }^{47}$ MD rehabilitation for fatigue should focus on the underlying cause and include education to improve self-management, task simplification and energy conservation strategies. ${ }^{45-47}$

\section{Psychosocial issues}

The common psychological issues in BC survivors include anxiety, depression, stress, altered emotional reactions, sleep disturbance and social isolation. ${ }^{19,20,49}$ These psychosocial responses may be due to pain, ${ }^{50}$ treatment side effects, especially chemotherapy, ${ }^{51}$ early onset menopause and fertility concerns, and concerns regarding disease recurrence and/ or metastasis. ${ }^{52,53}$ It can affect a woman's body image and negatively impact sexual relationships. ${ }^{54}$ The reported rates for major depression are between $10 \%$ and $25 \%$ in women 
with $\mathrm{BC},{ }^{55}$ and at 12 months post-diagnosis, the prevalence of either anxiety or depressive disorder can increase up to $30 \%{ }^{56}$ A longitudinal follow-up study of women with BC in the community (median time since diagnosis of 4.3 years) $(n=85)$, reported elevated levels of anxiety and depression (22\%), higher than in the normative population data. ${ }^{17}$ This was in contrast to previous reports showing a decrease in psychological distress ${ }^{57}$ and no change in rate of anxiety or depression or both over 5 years of follow-up. ${ }^{25}$ This variation may be attributed to methodological differences across studies. ${ }^{58}$ This has important clinical implications for long-term monitoring, education, cognitive behavioral therapy, support and counseling of the $\mathrm{BC}$ patients (and their families). ${ }^{17}$ Further, during the disease trajectory, other issues might surface, such as personal concerns (self-worth, self-image), coping with new demands associated with increased care needs, inability to return to driving and work, financial constraints, marital stress and restriction in participation in societal activities

\section{Evidence for rehabilitation interventions in BC}

Most $\mathrm{BC}$ patients are expected to make a good recovery following definitive treatment; however, long-term physical and psychological morbidity associated with BC treatment can be underestimated. ${ }^{59}$ The main goal of cancer rehabilitation is to maximize patients' ability to function, promote their participation and improve QoL, irrespective of their survival period. ${ }^{47}$

A rehabilitation approach to $\mathrm{BC}$ includes a wide spectrum of treatment and use of different interventions. The role of rehabilitation in cancer generally is described widely in literature. ${ }^{11,22}$ Likewise, the beneficial effects of rehabilitation treatment for individuals with $\mathrm{BC}$ is well documented. The existing evidence for various specific rehabilitation interventions in $\mathrm{BC}$ are summarized below, and tabulated in Table 1, categorized according to study design using a hierarchy of evidence defined by the National Health and Medical Research Council program for intervention studies. ${ }^{60}$ Priority was given to high quality systematic reviews or meta-analyses and randomized controlled trials (RCTs).

\section{Multidisciplinary rehabilitation}

MD rehabilitation is defined as "the co-ordinated delivery of intervention, inpatient or ambulatory (outpatient, home or community-based program), by two or more disciplines (nursing, physiotherapy, occupational therapy, social work,

Table I Rehabilitation interventions in breast cancer

\begin{tabular}{|c|c|c|}
\hline Intervention & Beneficial effects & Level of evidence* \\
\hline Multidisciplinary rehabilitation & $\begin{array}{l}\text { Improvement of short-term (up to } 12 \text { months) disability (range of shoulder } \\
\text { movement), participation (psychosocial adjustment) and QoL }\end{array}$ & 1 \\
\hline \multicolumn{3}{|l|}{ Physical therapeutic modalities } \\
\hline Overall exercise & $\begin{array}{l}\text { Improvement of disability, mobility, maintenance of range of motion, fatigue } \\
\text { and QoL; no effect on incidence of postsurgical lymphedema }\end{array}$ & I \\
\hline Resistance training & $\begin{array}{l}\text { Improvement of muscle strength, mobility and QoL; preservation of bone } \\
\text { mineral density, improvement in psychological symptoms }\end{array}$ & 1 \\
\hline Endurance, aerobic training & Improvement of aerobic capacity, muscle strength, fatigue & I \\
\hline Compression bandage & Reduction in arm lymphedema volume & II \\
\hline $\begin{array}{l}\text { Psychosocial interventions: psycho- } \\
\text { education, cognitive behavioural therapy, } \\
\text { stress reduction programme }\end{array}$ & $\begin{array}{l}\text { Improvement in psychological status (depression, anxiety, fear of recurrence), } \\
\text { QoL, physical functioning }\end{array}$ & I \\
\hline $\begin{array}{l}\text { Occupational therapy, educational } \\
\text { programs }\end{array}$ & Improvement in ADLs, reduction of fatigue impact, increased self-efficacy & I \\
\hline \multicolumn{3}{|l|}{ Complementary therapies } \\
\hline Reflexology, massage & Improvement in physical functioning, symptoms, relaxation, QoL & II \\
\hline Yoga & $\begin{array}{l}\text { Improvement of psychosocial variables (emotional irritability, cognitive } \\
\text { disorganization, mood disturbance, tension, depression and confusion), } \\
\text { physical functioning }\end{array}$ & II \\
\hline Music therapy & $\begin{array}{l}\text { Short- and long-term positive effects on alleviating pain; short-term } \\
\text { improvement on cardiovascular functions }\end{array}$ & II \\
\hline Nutritional interventions & $\begin{array}{l}\text { No evidence for beneficial effects for BC related issues; however, benefits } \\
\text { of a healthy lifestyle include lowering the risk of heart disease, high blood } \\
\text { pressure, diabetes, osteoporosis, etc. }\end{array}$ & I \\
\hline Vocational rehabilitation & No conclusive evidence & I \\
\hline
\end{tabular}

Note: *Evidence categorized according to study design using evidence defined by the National Health and Medical Research Council (NHMRC) program for intervention studies. $^{60}$

Abbreviations: ADLs, activities of daily living; BC, breast cancer; QoL, quality of life. 
psychology, dietetics, etc.) under medical supervision (neurologist, oncologist, rehabilitation physician)". ${ }^{21} \mathrm{MD}$ rehabilitation is often individualized to cater to the changing needs of patients. It optimizes standard medical treatments (surgery, radiotherapy, chemotherapy) and aims to reduce complications, manage condition-related symptoms (such as pain, fatigue, etc.), and promotes physical modalities and psychosocial adjustment to maximize participation. ${ }^{21}$

Khan et al in a systematic review of MD care for $\mathrm{BC}$ patients, based on two trials, found "weak evidence" for inpatient MD rehabilitation in producing short-term gains at the levels of impairment (shoulder range of movement), psychosocial adjustment and QoL. ${ }^{21}$ The authors did not find any evidence on functional gains at the level of activity. The MD programs evaluated in these two trials included psychology-based education, physiotherapy, peer support group activity, dietetics, image consultant input and fitness training. Both included trials had multiple methodological flaws (such as unclear randomization, lack of concealed allocation and blinding procedures) and were categorized as of "poor quality". The authors did not find any evidence for the long-term efficacy or cost-effectiveness of these programs. The authors highlighted the need for future research in this area. Regular specialist evaluation and follow-up of the BC patients was recommended to assess the need for appropriate rehabilitation and maintenance therapy to maximize independent living and participation.

One RCT $(n=85)$ demonstrated evidence for an intensive ambulatory MD rehabilitation program (compared with usual treatment in the community-control group) in improving psychosocial adjustment and QoL after BC treatment. ${ }^{61}$ The BC survivors showed significant improvement in "participation" domains (depression, mobility and societal participation) and QoL, up to 4 months. There was no change in "activity," probably due to the high functioning BC participants in the community. The individualized MD rehabilitation program included physiotherapy for strengthening and maintaining shoulder range of movement, lymphedema care, occupational therapy for energy conservation and task re-acquisition strategies to improve everyday function (domestic, community tasks), driving and return to work, and clinical psychology for counseling, coping and supportive strategies.

\section{Physical therapy}

Physical therapies are aimed at improving overall functional capacity, upper extremity strength and shoulder joint ROM, decreasing pain and management of lymphedema. A number of reviews support the effectiveness of exercise in $\mathrm{BC}$ patients (with or without lymphedema), in reducing treatment complications, fatigue and de-conditioning. ${ }^{43,62-65}$ Juvet et al in a systematic review ( $\mathrm{n}=25 \mathrm{RCTs}, 3418$ participants) reported that an exercise intervention program can produce short-term improvements in physical functioning and can reduce fatigue in persons with BC. ${ }^{65}$ One systematic review ( $\mathrm{n}=9$ trials) reported the beneficial effects of exercise during adjuvant treatment for $\mathrm{BC}$, and improved physical fitness and thus the capacity for performing activities of daily livings, which may, otherwise, be impaired due to inactivity during treatment. ${ }^{66}$ There was, however, no evidence regarding improving fatigue, psychosocial distress and physiological changes. ${ }^{66}$ Another systematic review ( $n=24$ trials) reported the effectiveness and safety of exercise for upper limb dysfunction and improved shoulder ROM due to BC treatment. ${ }^{43}$ Physical therapy yielded long-term additional benefit for shoulder function following the intervention for up to 6 months and there was no evidence of increased risk of lymphedema. The need for early implementation of exercises in the postoperative period should be weighed against the potential for increase in wound drainage volume and duration. Patterson et al ( $n=2343$ participants) found that improvement in selfreported physical health predicted longer survival in women with BC. ${ }^{67}$ Chan et al reported that early introduction of exercises was valuable in avoiding deterioration in range of shoulder motion; however, this did not affect the incidence of post-operative lymphedema. ${ }^{68}$

A systematic review $(n=15$ trials) found combined physical therapeutic modalities were an effective treatment for patients with arm lymphedema secondary to axillary dissection. ${ }^{69}$ These modalities included an intensive phase, consisting of skin care, manual lymphatic drainage, exercises and bandaging, and a maintenance phase comprising skin care, exercises, wearing a compression sleeve and manual lymphatic drainage if needed ${ }^{69}$ However, the effectiveness of different components remains uncertain. There was no evidence for the long-term effect of intermittent pneumatic compression and elevation. Moseley et al, in another systematic review, reported similar results. ${ }^{36}$ The optimum timing for physical exercise of the affected upper limb after BC surgery is unclear. Treatment initiated at 6 weeks postoperatively had similar outcomes to programs that commenced at 6 months after surgery. ${ }^{69}$

\section{External compression}

External compression such as compressive bandaging, intermittent pneumatic pressure devices, pressure gradient garments, manual compression in conjunction with specific 
therapy exercises and massage techniques, were used to treat peripheral lymphedema. ${ }^{70-73}$ The RCT by King et al found that both compression bandages and garments were beneficial for management of patients with moderate lymphedema, with compression bandaging more effective in reducing the lymphedema volume compared with compression garments. ${ }^{71}$ Similar results were reported in another RCT demonstrating a beneficial effect of combination compression bandaging and manual lymphatic drainage in reduction of arm lymphedema volume. ${ }^{73}$ Another RCT suggested that adjuvant treatment with pneumatic compression devices provided significantly better outcomes for the home maintenance phase of treatment of arm lymphedema secondary to BC therapy. ${ }^{70}$ It is suggested that caution should be exercised when applying these devices, as pain and hematomas are common at the involved site. ${ }^{72}$

\section{Psychosocial intervention}

Various forms of psychological interventions in BC survivors (such as education, individual psychotherapy, cognitive behavioral training and group interventions) has been trialled and have shown beneficial effects on negative perceptions, relationships and QoL. ${ }^{14,74}$ However, a systematic review of the effects of psychological interventions and survival outcomes for women with metastatic BC ( $\mathrm{n}=5$ studies) showed limited benefit. ${ }^{74}$ Evidence for group psychological interventions ( 2 cognitive behavioral interventions and 3 support-expressive group therapy interventions) showed benefit in the short-term; however, these were not sustained at follow-up. ${ }^{74}$ These findings are similar to those of other reports examining the effect on cancer survival rate of psychological interventions. ${ }^{75,76}$ Uitterhoeve et al, in another systematic review ( $n=12$ trials), reported positive effects of behavioral therapy (psychosocial intervention) on QoL indicators, including depression. ${ }^{77}$ Another RCT demonstrated favorable effects of group cognitive behavioral therapy in reducing problematic hot flashes and night sweats after BC treatment, with additional benefits to mood, sleep and QoL. ${ }^{77}$

\section{Complementary therapies}

Complementary therapies (such as relaxation, music, distraction, massage, recreation, heat and cold therapy) are reported as being effective in controlling symptoms in BC survivors. ${ }^{14,78}$ A systematic review ( $n=5$ trials) found a positive effect of different interventions (acupuncture, yoga, art therapy or relaxation training) on QoL and mood outcomes after BC treatment. ${ }^{78}$ Another study reported that relaxation training and acupuncture intervention reduced hot flashes. ${ }^{79}$ One RCT of hypnosis therapy for 5 weeks showed significantly decreased hot flash scores and improved anxiety, depression, interference of hot flashes on daily activities and sleep. ${ }^{46}$

There are reports of beneficial effects of yoga and music in managing cancer-related symptoms and treatments. ${ }^{80-82}$ One RCT demonstrated significant improvements in fatigue and vigor among $\mathrm{BC}$ survivors with persistent fatigue symptoms with targeted yoga. ${ }^{83}$ Other RCTs reported the beneficial effects of yoga in physical and psychosocial outcomes (emotion, stress, coping, etc.). ${ }^{84-86}$ One study showed that music therapy in patients undergoing chemotherapy treatment resulted in significant improvements in anxiety, fear, fatigue, relaxation, diastolic blood pressure and improved QoL. ${ }^{87}$

\section{Nutrition}

Weight gain and body composition changes are common in the $\mathrm{BC}$ population and are associated with a higher risk of adverse clinical outcomes. ${ }^{78,88}$ Despite this, there is limited research on preventive and therapeutic interventions targeting reduction in weight and/or body fat. ${ }^{88} \mathrm{~A}$ systematic review $(n=2$ trials) found insufficient evidence for the effectiveness of nutritional interventions for BC survivors after primary cancer treatment. However, the benefits of a healthy lifestyle go far beyond lowering cancer risk, and include lowering the risk of heart disease, high blood pressure, diabetes, osteoporosis, etc. ${ }^{78}$

\section{Vocational rehabilitation}

With improved BC management over the past decades, the number of BC survivors who work has increased considerably. However, efforts aimed at stimulating vocational rehabilitation (re-employment and return-to-work interventions) for BC survivors have been evaluated in only a few studies. A systematic review ${ }^{89}$ of outcomes of vocational programs in the $\mathrm{BC}$ population was inconclusive due to lack of methodologically sound studies and lack of the outcomes that addressed return to work. The authors concluded that clinicians need to be aware of vocational issues in this population, and understand and manage barriers for maintaining employment. ${ }^{89}$

\section{Discussion}

Due to therapeutic advances in BC management, survival rates of $\mathrm{BC}$ patients have increased significantly; however, many can present with diverse clinical problems and varying levels of disability during their disease trajectory that require an individualized rehabilitation for longer period. Furthermore, due to the heterogeneity in clinical presentations, 
patients' and/or caregivers' perspectives need to be incorporated in the rehabilitation programs, not only for better outcomes, but also to facilitate communication and agreement among treating clinicians. ${ }^{21}$

The ICF framework (Figure 1) provides an opportunity to improve clinical agreement and communication among MD teams. An expert consensus identified the "core set" for BC (lists of ICF categories selected by experts for targeted management) that need to be addressed in clinical settings. ${ }^{90}$ One report of women after BC treatment linked patient-reported problems with the concepts contained within specific ICF categories in various domains to provide information considered essential by patients for targeted treatment. ${ }^{91}$ The findings provided a broader patient perspective and found 13 additional categories in the components "Activities and Participation" and "Environmental factors" for possible inclusion in the comprehensive core set for BC. ${ }^{91}$ The authors argued that assessment of the $\mathrm{BC}$ population needs to reflect these complex constructs, as advocated by WHO ICF. ${ }^{12}$ Many commonly used outcome measures in rehabilitation settings (e.g., the Functional Independence Measure or Barthel Index) tend to have floor/ceiling effects and may not be sensitive enough to capture the relevant gains following interventions. In particular, in the $\mathrm{BC}$ population, QoL is difficult to measure given the many contributing and confounding factors. ${ }^{92-94}$ There is a need for more research in the $\mathrm{BC}$ population to obtain consensus on a suitable battery of measures to capture change in physical ability, and longterm outcomes relating to psychosocial adjustment and QoL.

Many rehabilitation interventions are complex in nature and the active ingredient within the intervention is not easily identifiable. ${ }^{95}$ Methodologically robust trials to support rehabilitation intervention in women with $\mathrm{BC}$ are limited. There are many challenges in evaluating rehabilitation interventions in the $\mathrm{BC}$ population, including: heterogeneous patient populations, multiple complex issues requiring longterm care (such as survivorship), multiple symptoms (pain, lymphedema, limited shoulder mobility, fatigue, etc.) and profound psychological issues, interdependent components and contexts, multifaceted and multilayered treatments involving organizational restructure, individualized interventions and ethical considerations. ${ }^{61}$

Cancer registries exist in many countries and mainly contain survival, medical and treatment outcome data. However, information about residual disability and restriction in participation after BC treatment is not routinely available. This includes rehabilitation interventions and palliative care input, especially over the longer term. In Australia, a national rehabilitation dataset collates inpatient and ambulatory data from over 180 accredited public and private rehabilitation facilities across the country through the Australasian Rehabilitation Outcomes Centre, which currently provides generic measures of global disability and only essential rehabilitation outcome data (such as the degree of reduction in disability, hospital length of stay and discharge destinations). Further information in specific domains relevant to specific patient cohorts such as BC survivors and outcomes will be needed to make this dataset more clinically relevant.

As aforementioned, physical and psychosocial sequelae are common in the $\mathrm{BC}$ population, which is amenable to specialized rehabilitation programs. Gaps in communication between members of the MD treating team in rehabilitation services have been reported. ${ }^{96}$ There is a need for innovations that offer paradigm shifts in the delivery of timely, cost- effective, patient-centered and sustainable rehabilitative care for this vulnerable patient cohort. This can be achieved through a holistic integrated long-term approach incorporating surgical/ oncological and rehabilitation treating teams. Participation limitations of $\mathrm{BC}$ survivors need particular attention that requires education and support for women with $\mathrm{BC}$, and their treating MD teams.

In conclusion, there is increasing awareness of rehabilitation in early and long-term management for BC survivors. Various rehabilitative approaches in BC survivors, including MD rehabilitation and specific rehabilitation interventions, such as physical therapy and psychosocial interventions, have shown to be beneficial in restoring and/or improving functional ability, participation and QoL. Overall, rehabilitation approach for BC survivors need a holistic approach and should include functional goal-oriented method to target patient priorities, delivered by MD team. There are still many challenges in examining the "black box" of rehabilitation programs. Though, rehabilitation interventions are often routinely provided, many are difficult to standardize and define, and measuring the types of approaches that are effective (settings, intensity) is still a challenge. More rigorous research is needed to determine the effectiveness of specific rehabilitation interventions (and emerging therapies), contextual factors impacting adjustment and the societal burden of long-term care of BC survivors and their families/carers.

\section{Acknowledgment}

This review was supported from internal resources of the Rehabilitation Department, Royal Melbourne Hospital, Royal Park Campus, Melbourne, Australia. 


\section{Disclosure}

The authors report no conflicts of interest in this work.

\section{References}

1. International Agency for Research on Cancer. Globocan 2008. Estimated cancer incidence, mortality, prevalence and disability-adjusted life years (DALYs) worldwide in 2008; 2012. Available from: http://globocan. iarc.fr/. Accessed January 20, 2017.

2. Australian Institute of Health and Welfare (AIHW). Breast cancer in Australia: an overview. National Breast and Ovarian Cancer Centre, Cancer Series no 50. Cat no CAN 46. Canberra, Australia: AIHW; 2009.

3. World Health Organisation. The Global Burden of Disease: 2004 Update. Geneva: WHO; 2008.

4. Danaei G, Vander Hoorn S, Lopez AD, Murray CJ, Ezzati M. Causes of cancer in the world: comparative risk assessment of nine behavioural and environmental risk factors. Lancet. 2005;366(9499):1784-1793.

5. Maughan KL, Lutterbie MA, Ham PS. Treatment of breast cancer. Am Fam Physician. 2010;81(11):1339-1346.

6. Yip C, Smith RA, Anderson BO, et al. Guideline implementation for breast healthcare in low- and middle-income countries: early detection resource allocation. Cancer. 2009;113(8 Suppl):2244-2256.

7. Wade DT. Measurement in Neurological Rehabilitation. London: Oxford University Press; 1992.

8. National Institute for Clinical Excellence. Improving Supportive and Palliative Care for Adults with Cancer. London: NICE; 2004.

9. iSource National Breast Cancer Centre. Clinical Practice Guidelines for the Management of Early Breast Cancer: 2nd edition. 2001. Available from: http:/www.nhmrc.gov.au/_files_nhmrc/publications/attachments/ cp76.pdf. Accessed January 20, 2017.

10. National Institute for Clinical Excellence. Improving Outcomes in Breast Cancer. London: NICE; 2002.

11. Gerber LH, Vargo MM, Smith RG. Rehabilitation of the cancer patient. In: De Vita V, Hellman S, Rosenberg S, editors. Cancer: Principles and Practice of Oncology. 7th ed. NY: Lippincott Williams and Wilkins; 2005:2719-2746.

12. World Health Organization (WHO). The International Classification of Functioning, Disability and Health (ICF). Geneva: WHO; 2001.

13. Campbell KL, Pusic AL, Zucker DS, et al. A prospective model of care for breast cancer rehabilitation: function. Cancer. 2012;118(8 Suppl):2300-2311.

14. Chung BY, Xu Y. Developing a rehabilitation model of breast cancer patients through literature review and hospital rehabilitation programs. Asian Nurs Res (Korean Soc Nurs Sci). 2008;2(1):55-67.

15. Arora NK, Gustafson DH, Hawkins RP, et al. Impact of surgery and chemotherapy on the quality of life of younger women with breast carcinoma: a prospective study. Cancer. 2001;92(5):1288-1298.

16. Janz NK, Mujahid MS, Hawley ST, et al. Racial/ethnic differences in quality of life after diagnosis of breast cancer. J Cancer Surviv. 2009;3(4):212-222.

17. Khan F, Amatya B, Pallant JF, Rajapaksa I. Factors associated with long-term functional outcomes and psychological sequelae in women after breast cancer. Breast. 2012;21(3):314-320.

18. Kwan ML, Ergas IJ, Somkin CP, et al. Quality of life among women recently diagnosed with invasive breast cancer: the Pathways Study. Breast Cancer Res Treat. 2010;123(2):507-524.

19. Ganz PA, Desmond KA, Leedham B, Rowland JH, Meyerowitz BE, Belin TR. Quality of life in long-term, disease-free survivors of breast cancer: a follow-up study J Natl Cancer Inst. 2002;94(1):39-49.

20. Vos PJ, Visser AP, Garssen B, Duivenvoorden HJ, de Haes HC. Effects of delayed psychosocial interventions versus early psychosocial interventions for women with early stage breast cancer. Patient Educ Couns. 2006;60(2):212-219.

21. Khan F, Amatya B, Ng L, Demetrios M, Zhang NY, Turner-Stokes L. Multidisciplinary rehabilitation for follow-up of women treated for breast cancer. Cochrane Database Syst Rev. 2012;(12):CD009553
22. Franklin DJ. Cancer rehabilitation: challenges, approaches and new directions. Phys Med Rehabil Clin N Am. 2007;18(4):899-924.

23. MacDonald L, Bruce J, Scott NW, Smith WC, Chambers W. Long term follow-up of breast cancer survivors with post mastectomy pain syndrome. Br J Cancer. 2005;92(2):225-230.

24. Tager FA, McKinley PS, Schnabel FR, et al. The cognitive effects of chemotherapy in post-menopausal breast cancer patients: a controlled longitudinal study. Breast Cancer Res Treat. 2010;123(1):25-34.

25. Hopwood P, Sumo G, Mills J, Haviland J, Bliss JM. The course of anxiety and depression over 5 years of follow up and risk factors in women with early breast cancer: results from the UK Standardisation of Radiotherapy Trials (START). Breast. 2010;19(2):84-91.

26. Nesvold IL, Reinertsen KV, Fossa SD, Dahl AA. The relation between arm/shoulder problems and quality of life in breast cancer survivors: a cross-sectional and longitudinal study. J Cancer Surviv. 2011;5(1):62-72.

27. Sagen A, Karesen R, Sandvik L, Risberg MA. Changes in arm morbidities and health-related quality of life after breast cancer surgery - a five-year follow-up study. Acta Oncol. 2009;48(8):1111-1118.

28. Carpenter JS, Andrykowski MA, Sloan P, et al. Post mastectomy/post lumpectomy pain in breast cancer survivors. JClin Epidemiol. 1998;51(12): 1285-1292.

29. Rief W, Bardwell WA, Dimsdale JE, Natarajan L, Flatt SW, Pierce JP. Long-term course of pain in breast cancer survivors: a 4-year longitudinal study. Breast Cancer Res Treat. 2011;130(2):579-586.

30. Jung BF, Herrmann D, Griggs J, Oaklander AL, Dworkin RH. Neuropathic pain associated with non-surgical treatment of breast cancer. Pain. 2005;118(1-2):10-14.

31. Stevens PE, Dibble SL, Miaskowski C. Prevalence, characteristics, and impact of postmastectomy pain syndrome: an investigation of women's experiences. Pain. 1995;61(1):61-68.

32. Poleshuck EL, Katz J, Andrus CH, et al. Risk factors for chronic pain following breast cancer surgery: a prospective study. J Pain. 2006;7(9):626-634.

33. Stubblefield MD, Custodio CM. Upper-extremity pain disorders in breast cancer. Arch Phys Med Rehabil. 2006;87(3 Suppl 1):S96-S99; quiz S100-S101.

34. Caffo O, Amichetti M, Ferro A, Lucenti A, Valduga F, Galligioni E. Pain and quality of life after surgery for breast cancer. Breast Cancer Res Treat. 2003;80(1):39-48.

35. Robb KA, Williams JE, Duvivier V, Newham DJ. A pain management program for chronic cancer-treatment-related pain: a preliminary study. J Pain. 2006;7(2):82-90.

36. Moseley AL, Carati CJ, Piller NB. A systematic review of common conservative therapies for arm lymphoedema secondary to breast cancer treatment. Ann Oncol. 2007;18(4):639-646.

37. Mortimer PS. The pathophysiology of lymphedema. Cancer. 1998;83(12 Suppl American):2798-2802.

38. Schmitz KH, Troxel AB, Cheville A, et al. Physical activity and lymphedema (the PAL trial): assessing the safety of progressive strength training in breast cancer survivors. Contemp Clin Trials. 2009;30(3):233-245.

39. Stamatakos M, Stefanaki C, Kontzoglou K. Lymphedema and breast cancer: a review of the literature. Breast Cancer. 2011;18(3): $174-180$.

40. Williams AF, Franks PJ, Moffatt CJ. Lymphoedema: estimating the size of the problem. Palliat Med. 2005;19(4):300-313.

41. Rockson SG, Miller LT, Senie R, et al. American Cancer Society Lymphedema Workshop. Workgroup III: diagnosis and management of lymphedema. Cancer. 1998;83(12 Suppl):2882-2885.

42. Petrek JA, Senie RT, Peters M, Rosen PP. Lymphedema in a cohort of breast carcinoma survivors 20 years after diagnosis. Cancer. 2001;92(6):1368-1377.

43. McNeely ML, Campbell K, Ospina M, et al. Exercise interventions for upper-limb dysfunction due to breast cancer treatment. Cochrane Database Syst Rev. 2010;(6):CD005211. 
44. Lee TS, Kilbreath SL, Refshauge KM, Herbert RD, Beith JM. Prognosis of the upper limb following surgery and radiation for breast cancer. Breast Cancer Res Treat. 2008;110(1):19-37.

45. Berger AM, Gerber LH, Mayer DK. Cancer-related fatigue: implications for breast cancer survivors. Cancer. 2012;118(8 Suppl): 2261-2269.

46. Elkins G, Marcus J, Stearns V, et al. Randomized trial of a hypnosis intervention for treatment of hot flashes among breast cancer survivors. J Clin Oncol. 2008;26(31):5022-5026.

47. Silver JK. Rehabilitation in women with breast cancer. Phys Med Rehabil Clin NAm. 2007;18(3):521-537.

48. Siefert ML. Fatigue, pain, and functional status during outpatient chemotherapy. Oncol Nurs Forum. 2010;37(2):E114-E123.

49. Schnipper HH. Life after breast cancer. J Clin Oncol. 2001;19(15): 3581-3584

50. Reddick BK, Nanda JP, Campbell L, Ryman DG, Gaston-Johansson F. Examining the influence of coping with pain on depression, anxiety, and fatigue among women with breast cancer. J Psychosoc Oncol. 2005; 23(2-3):137-157.

51. Boehmke MM, Dickerson SS. Symptom, symptom experiences, and symptom distress encountered by women with breast cancer undergoing current treatment modalities. Cancer Nurs. 2005;28(5):382-389.

52. Baucom DH, Porter LS, Kirby JS, Gremore TM, Keefe FJ. Psychosocial issues confronting young women with breast cancer. Breast Disease. 2005-2006;23(1):103-113.

53. Peate M, Meiser B, Hickey M, Friedlander M. The fertility-related concerns, needs, and preferences of younger women with breast cancer: a systematic review. Breast Cancer Res Treat. 2009;116(2):215-223.

54. Sheppard LA, Ely S. Breast cancer and sexuality. Breast J. 2008; 14(2):176-181.

55. Fann J. Major depression after breast cancer: a review of epidemiology and treatment. Gen Hosp Psychiatry. 2008;30(2):112-126.

56. Bleiker EM, Pouwer F, van der Ploeg HM, Leer JW, Ader HJ. Psychological distress 2 years after diagnosis of breast cancer: frequency and prediction. Patient Educ Couns. 2000;40(3):209-217.

57. Burgess C, Cornelius V, Love S, Graham J, Richards M, Ramirez A. Depression and anxiety in women with early breast cancer: five year observational cohort study. BMJ. 2005;330(7493):702-705.

58. Jassim GA, Whitford DL, Grey IM. Psychological interventions for women with non-metastatic breast cancer. Cochrane Database Syst Rev. 2010;10:CD008729.

59. Loprinzi PD, Cardinal BJ. Effects of physical activity on common side effects of breast cancer treatment. Breast Cancer. 2012;19(1): $4-10$.

60. National Health and Medical Research Council (NHMRC). NHMRC Levels of Evidence and Grades for Recommendations for Developers of Guidelines; 2009. Available from: http://www.nhmrc.gov.au/_files_ nhmrc/file/guidelines/evidence_statement_form.pdf. Accessed February 14, 2017.

61. Khan F, Amatya B, Pallant JF, Rajapaksa I, Brand C. Multidisciplinary rehabilitation in women following breast cancer treatment: a randomized controlled trial. J Rehabil Med. 2012;44(9):788-794.

62. Cheema B, Gaul CA, Lane K, Fiatarone Singh MA. Progressive resistance training in breast cancer: a systematic review of clinical trials. Breast Cancer Res Treat. 2008;109(1):9-26.

63. Loprinzi PD, Cardinal BJ, Winters-Stone K, Smit E, Loprinzi CL. Physical activity and the risk of breast cancer recurrence: a literature review. Oncol Nurs Forum. 2012;39(3):269-274.

64. Spence RR, Heesch KC, Brown WJ. Exercise and cancer rehabilitation: a systematic review. Cancer Treat Rev. 2010;36(2):185-194.

65. Juvet LK, Thune I, Elvsaas IKO, et al. The effect of exercise on fatigue and physical functioning in breast cancer patients during and after treatment and at 6 months follow-up: a meta-analysis. Breast. 2017;33:166-177.

66. Markes M, Brockow T, Resch KL. Exercise for women receiving adjuvant therapy for breast cancer. Cochrane Database Syst Rev. 2006;(4):CD005001.
67. Patterson RE, Saquib N, Natarajan L, et al. Improvement in self-reported physical health predicts longer survival among women with a history of breast cancer. Breast Cancer Res Treat. 2011;127(2):541-547.

68. Chan DN, Lui LY, So WK. Effectiveness of exercise programmes on shoulder mobility and lymphoedema after axillary lymph node dissection for breast cancer: systematic review. $J$ Adv Nurs. 2010;66(9):1902-1914.

69. Devoogdt N, Van Kampen M, Geraerts I, Coremans T, Christiaens M-R. Different physical treatment modalities for lymphoedema developing after axillary lymph node dissection for breast cancer: a review. Eur $J$ Obstet Gynecol Reprod Biol. 2010;149(1):3-9.

70. Fife CE, Davey S, Maus EA, Guilliod R, Mayrovitz HN. A randomized controlled trial comparing two types of pneumatic compression for breast cancer-related lymphedema treatment in the home. Support Care Cancer. 2012;20(12):3279-3286.

71. King M, Deveaux A, White H, Rayson D. Compression garments versus compression bandaging in decongestive lymphatic therapy for breast cancer-related lymphedema: a randomized controlled trial. Support Care Cancer. 2012;20(5):1031-1036.

72. Damstra RJ, Partsch H. Compression therapy in breast cancer-related lymphedema: a randomized, controlled comparative study of relation between volume and interface pressure changes. J Vasc Surg. 2009;49(5):1256-1263.

73. McNeely ML, Magee DJ, Lees AW, Bagnall KM, Haykowsky M, Hanson J. The addition of manual lymph drainage to compression therapy for breast cancer related lymphedema: a randomized controlled trial. Breast Cancer Res Treat. 2004;86(2):95-106.

74. Edwards AGK, Hulbert-Williams N, Neal R. Psychological interventions for women with metastatic breast cancer. Cochrane Database Syst Rev. 2008;(3):CD004253.

75. Chow E, Tsao MN, Harth T. Does psychosocial intervention improve survival in cancer? A meta-analysis. Palliat Med. 2004;18(1):25-31.

76. Smedslund G, Ringdal GI. Meta-analysis of the effects of psychosocial interventions on survival time in cancer patients. $J$ Psychosom Res. 2004;57(2):123-131; discussion 133-125.

77. Uitterhoeve RJ, Vernooy M, Litjens M, et al. Psychosocial interventions for patients with advanced cancer - a systematic review of the literature. Br J Cancer. 2004;91(6):1050-1062.

78. Norwegian Knowledge Centre for the Health Services. Rehabilitation of Breast Cancer Patients: Systematic Review. Oslo: Kunnskapssenteret; 2009.

79. Kovacic T, Kovacic M. Impact of relaxation training according to Yoga In Daily Life(R) system on self-esteem after breast cancer surgery. J Altern Complement Med. 2011;17(12):1157-1164.

80. Carson JW, Carson KM, Porter LS, Keefe FJ, Seewaldt VL. Yoga of awareness program for menopausal symptoms in breast cancer survivors: results from a randomized trial. Support Care Cancer. 2009;17(10):1301-1309.

81. Carson JW, Carson KM, Porter LS, Keefe FJ, Shaw H, Miller JM. Yoga for women with metastatic breast cancer: results from a pilot study. J Pain Symptom Management. 2007;33(3):331-341.

82. Daykin N, McClean S, Bunt L. Creativity, identity and healing: participants' accounts of music therapy in cancer care. Health (London). 2007;11(3):349-370.

83. Bower JE, Garet D, Sternlieb B, et al. Yoga for persistent fatigue in breast cancer survivors: a randomized controlled trial. Cancer. 2012;118(15): 3766-3775.

84. Kovacic T, Kovacic M. Impact of relaxation training according to Yoga In Daily Life(R) system on perceived stress after breast cancer surgery. Integr Cancer Ther. 2011;10(1):16-26.

85. Banerjee B, Vadiraj HS, Ram A, et al. Effects of an integrated yoga program in modulating psychological stress and radiation-induced genotoxic stress in breast cancer patients undergoing radiotherapy. Integr Cancer Ther. 2007;6(3):242-250.

86. Culos-Reed SN, Carlson LE, Daroux LM, Hately-Aldous S. A pilot study of yoga for breast cancer survivors: physical and psychological benefits. Psychooncology. 2006;15(10):891-897. 
87. Ferrer AJ. The effect of live music on decreasing anxiety in patients undergoing chemotherapy treatment. JMusic Ther. 2007;44(3):242-255.

88. Rooney M, Wald A. Interventions for the management of weight and body composition changes in women with breast cancer. Clin J Oncol Nurs. 2007;11(1):41-52.

89. Hoving JL, Broekhuizen ML, Frings-Dresen MH. Return to work of breast cancer survivors: a systematic review of intervention studies. BMC Cancer. 2009;9:117.

90. Brach M, Cieza A, Stucki G, et al. ICF core sets for breast cancer. J Rehabil Med. 2004(44 Suppl):121-127.

91. Khan F, Amatya B, Ng L, Demetrios M, Pallant JF. Relevance and completeness of the international classification of functioning, disability and health (ICF) comprehensive breast cancer core set: the patient perspective in an Australian community cohort. J Rehabil Med. 2012;44(7):570-580.
92. Campbell HS, Sanson-Fisher R, Turner D, Hayward L, Wang XS, Taylor-Brown J. Psychometric properties of cancer survivors' unmet needs survey. Support Care Cancer. 2010;19(2):221-230.

93. Hodgkinson K, Butow P, Hunt G, Pendlebury S, Hobbs K, Wain G. Breast cancer survivors supportive care needs $2-10$ years after diagnosis. Support Care Cancer. 2007;15(5):515-523.

94. Schag CA, Ganz PA, Heinrich RL. Cancer rehabilitation evaluation system-short form (CARES-SF): a cancer specific rehabilitation and quality of life instrument. Cancer. 1991;68(6):1406-1413.

95. Medical Research Council (MRC). A framework for development and evaluation of RCTs for complex interventions to improve health. London: MRC; 2000.

96. Braden CJ, Mishel MH, Longman AJ. Self-help intervention project. Women receiving breast cancer treatment. Cancer Pract. $1998 ; 6(2): 87-98$
Journal of Multidisciplinary Healthcare

\section{Publish your work in this journal}

The Journal of Multidisciplinary Healthcare is an international, peerreviewed open-access journal that aims to represent and publish research in healthcare areas delivered by practitioners of different disciplines. This includes studies and reviews conducted by multidisciplinary teams as well as research which evaluates the results or conduct of such teams or health

\section{Dovepress}

care processes in general. The journal covers a very wide range of areas and welcomes submissions from practitioners at all levels, from all over the world The manuscript management system is completely online and includes a very quick and fair peer-review system. Visit http://www.dovepress.com/ testimonials.php to read real quotes from published authors. 